\title{
Assurance complète pour votre cabinet
}

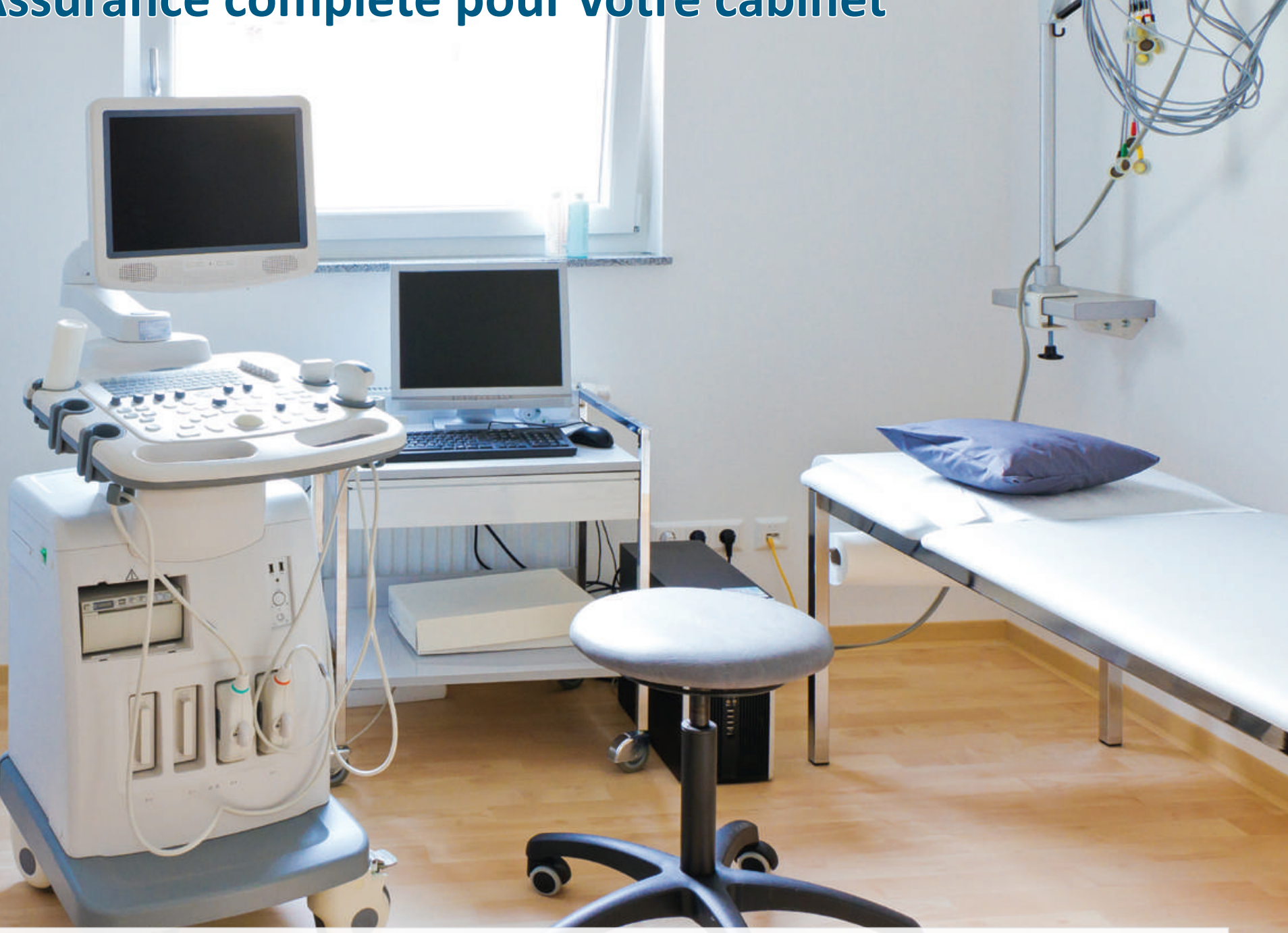

Connaissez-vous l'assurance pour cabinet de FMH Insurance Services laquelle a été spécialement élaborée pour les besoins du corps médical ? Par ce biais, les membres de FMH Services profitent de conditions spéciales et attractives. C'est avec plaisir que nous pouvons vous établir - sans frais ni engagement - une offre comparative à votre solution actuelle afin de vous démontrer votre potentiel d'épargne. Vérifiez notre offre afin d'être assuré au mieux et d'économiser des primes en même temps!

\section{ASSURANCE CABINET MÉDICAL}

$\square \quad$ Je souhaite recevoir une offre d'assurance pour cabinet de FMH Insurance Services - sans frais ni engagement. (Veuillez annexer une copie de votre police d'assurance actuelle).

$\square \quad$ Veuillez m’appeler pour un conseil personnalisé

Prénom / nom

Adresse

NPA / lieu

Téléphone privé / cabinet

Atteignable le plus facilement

Adresse e-mail

Talon réponse: prière d'envoyer ou de faxer au 0319595010

\section{FMH INSURANCE}

Roth Gygax \& Partner AG - Service de coordination Moosstrasse 2, 3073 Gümligen

Tél. 0319595000 - Fax 0319595010

mail@fmhinsurance.ch - www.fmhinsurance.ch 